\title{
BMJ Open Clinical management of unruptured intracranial aneurysm in Germany: a nationwide observational study over a 5-year period (2005-2009)
}

\author{
Victor Walendy, ${ }^{1}$ Andreas Stang ${ }^{1,2}$
}

To cite: Walendy V, Stang A. Clinical management of unruptured intracranial aneurysm in Germany: a nationwide observational study over a 5 -year period (2005-2009). BMJ Open 2017;7:e12294. doi:10.1136/bmjopen-2016012294

- Prepublication history and additional material is available. To view please visit the journal (http://dx.doi.org/ 10.1136/bmjopen-2016012294).

Received 14 April 2016 Revised 21 September 2016 Accepted 29 September 2016

CrossMark

\footnotetext{
${ }^{1}$ Zentrum für Klinische Epidemiologie, Universitätsklinikum Essen, Universität Duisburg-Essen, Essen, Germany ${ }^{2}$ Department of Epidemiology, School of Public Health, Boston University, Boston, Massachusetts, USA

Correspondence to Dr Andreas Stang; andreas.stang@uk-essen.de
}

\section{ABSTRACT}

Objectives: Our aim was to provide nationwide agestandardised rates (ASR) on the usage of endovascular coiling and neurosurgical clipping for unruptured intracranial aneurysm (UIA) treatment in Germany. Setting: Nationwide observational study using the Diagnosis-Related-Groups (DRG) statistics for the years 2005-2009 (overall 83 million hospitalisations).

Participants: From 2005 to 2009, overall 39155 hospitalisations with a diagnosis of UIA occurred in Germany.

Primary outcome measures: Age-specific and age-standardised hospitalisation rates for UIA with the midyear population of Germany in 2007 as the standard.

Results: Of the 10221 hospitalisations with UIA during the observation period, 6098 (59.7\%) and 4123 $(40.3 \%)$ included coiling and clipping, respectively. Overall hospitalisation rates for UIA increased by $39.5 \%(95 \% \mathrm{Cl} 24.7 \%$ to $56.0 \%)$ and $50.4 \%(95 \% \mathrm{Cl}$ $39.6 \%$ to $62.1 \%$ ) among men and women, respectively. In 2005, the ASR per 100000 person years for coiling was $0.7(95 \% \mathrm{Cl} 0.62$ to 0.78$)$ for men and $1.7(95 \% \mathrm{Cl} 1.58$ to 1.82$)$ for women. In 2009, the ASR was $1.0(95 \% \mathrm{Cl} 0.90$ to 1.10$)$ and 2.4 ( $95 \% \mathrm{Cl} 2.24$ to 2.56 ), respectively. Similarly, the ASR for clipping in 2005 amounted to $0.6(95 \% \mathrm{Cl} 0.52$ to $0.68)$ for men and $1.1(95 \% \mathrm{Cl} 1.00$ to 1.20$)$ for women. These rates increased in 2009 to $0.8(95 \% \mathrm{Cl}$ 0.72 to 0.88 ) and 1.7 (95\% $\mathrm{Cl} 1.58$ to 1.82$)$, respectively. We observed a marked geographical variation of ASR for coiling and less pronounced for clipping. For the federal state of Saarland, the ASR for coiling was 5.64 (95\% Cl 4.76 to 6.52$)$ compared with 0.68 ( $95 \% \mathrm{Cl} 0.48$ to 0.88 ; per 100000 person years) in Saxony-Anhalt, whereas, ASR for clipping were highest in Rhineland-Palatinate $(2.48,95 \% \mathrm{Cl} 2.17$ to $4.75)$ and lowest in Saxony-Anhalt $(0.52,95 \% \mathrm{Cl} 0.34$ to 0.70 ).

Conclusions: To the best of our knowledge, we presented the first representative, nationwide analysis of the clinical management of UIA in Germany. The ASR increased markedly and showed substantial geographical variation among federal states for all treatment modalities during the observation period.

\section{Strengths and limitations of this study}

- A major strength of this study is the large data set, which includes virtually all German hospitals.

- This allows a unique view at the current clinical practice from a population-based viewpoint.

- We used routine hospitalisation data; we were not able to fully address potential confounding as some important clinical factors were not available in the data.

- We assessed comorbidity based on the coded International Classification of Diseases, 10th Edition (ICD-10) diagnosis, comorbidity may be under-reported in the Diagnosis-Related-Groups (DRG) statistics.

\section{INTRODUCTION}

Unruptured intracranial aneurysms (UIAs) are a common cerebrovascular condition. With an estimated prevalence of $2 \%$ in the general population ${ }^{1}$ the number of individuals harbouring UIA would amount to $~ 1.6$ million individuals in Germany. Published data of a nationwide inpatient database from the USA showed a paradigm shift from surgical to endovascular UIA treatment. ${ }^{2}{ }_{3}$ Furthermore, it was observed that endovascular aneurysm treatment is becoming increasingly available in low volume centres. ${ }^{4} 5$ Despite these important changes, representative data on the usage of endovascular or surgical UIA treatment in Germany are sparse. Until now knowledge on the topic is mostly based on data of the Nationwide Inpatient Sample from the USA, ${ }^{2} 3$ 6-9 which represents a $20 \%$ stratified sample of US community hospitals. Using Diagnosis-Related-Groups (DRG) hospital data is a unique opportunity to assess the nationwide management of UIA.

Our aim was to provide nationwide and regional crude, age-specific and agestandardised hospitalisation rates on the 
usage of endovascular coiling and neurosurgical clipping for the treatment of UIA in Germany from 2005 to 2009. Furthermore, we determined the influence of age and gender on the rates. In addition, we ascertained the in-hospital mortality and length of stay (LOS) associated with coiling or clipping. Finally, we assessed the frequency of cerebrospinal fluid (CSF) shunt implantation as a known complication of UIA treatment, according to treatment modality.

\section{METHODS}

Data source

In 2004 a DRG-based reimbursement system for German hospitals became statutory. The amendment of the Hospital Reimbursement Act (KHEntgG) and the implementation of the Case Fees Act (FPG) formed the foundation of these changes. As stated in \$21 KHEntgG, all hospitals submit their hospitalisation data annually to the Hospital Remuneration System (InEK). After submission, a plausibility control of the data is carried out by InEk. In this process, the data is anonymised and forwarded to the Federal Bureau of Statistics. The submission of hospitalisation data is mandatory for reimbursement of hospital stays. This leads to a strong incentive for hospitals to supply complete data, in particular for expensive hospital stays. We analysed 83.01 million hospitalisations for the years 2005- 2009 in this study covering virtually all hospitals in Germany. The structure of DRG data supplied by the Federal Bureau of Statistics has been described in detail $^{10-12}$ (more information about the data source is available on http://www.forschungsdatenzentrum.de/ en/database/drg/index.asp).

\section{Cohort definition}

We analysed hospitalisations with a primary or secondary diagnosis of an UIA (International Classification of Diseases, 10th Edition, German Modification (ICD-10-GM): I67.10, Q28.20, Q28.30, Q28.80). Cases with an ICD-10 code indicating subarachnoid haemorrhage (ICD-10-GM: I60.-) were excluded. Subsequently we grouped all cases according to the coded procedures (Operationen- und Prozedurenschlüssel (OPS) V.2005 through 2009 OPS-Code: 8-836.m0 Coiling, 5-025.Clipping). If there was no procedure code, indicating coiling or clipping, a conservative treatment was assumed (figure 1). We additionally determined for all hospitalisations the placement of a temporary drainage of CSF (OPS-Code: 5-022.0), or the implantation of a permanent ventricular shunt (OPS-Code: 5-023.-). ${ }^{13}$ There were no changes of the classification of procedures throughout the observation period. From 83.01 million hospitalisations, we excluded 4397 (0.005\%) hospitalisations, because of missing data on gender, age, LOS, discharge or place of residence. Furthermore, we excluded $189214(0.22 \%)$ hospitalisations because of unknown place of residence and $650322(0.78 \%)$ hospitalisations were excluded because the indicated place of residence was outside of Germany.

We further excluded hospitalisations with conservative treatment of UIA (figure 1). We decided to omit this group from our analysis, as the reasons which led to hospitalisation are difficult to be assessed on the basis of DRG data. In hospitalisations for conservative treatment of UIA, follow-up examinations are likely to be the cause for admission in a large proportion of this group.
Figure 1 Study algorithm. aSAH, aneurysmal Subarachnoid Haemorrhage; DRG, Diagnosis-Related-Groups; UIA, unruptured intracranial aneurysm.

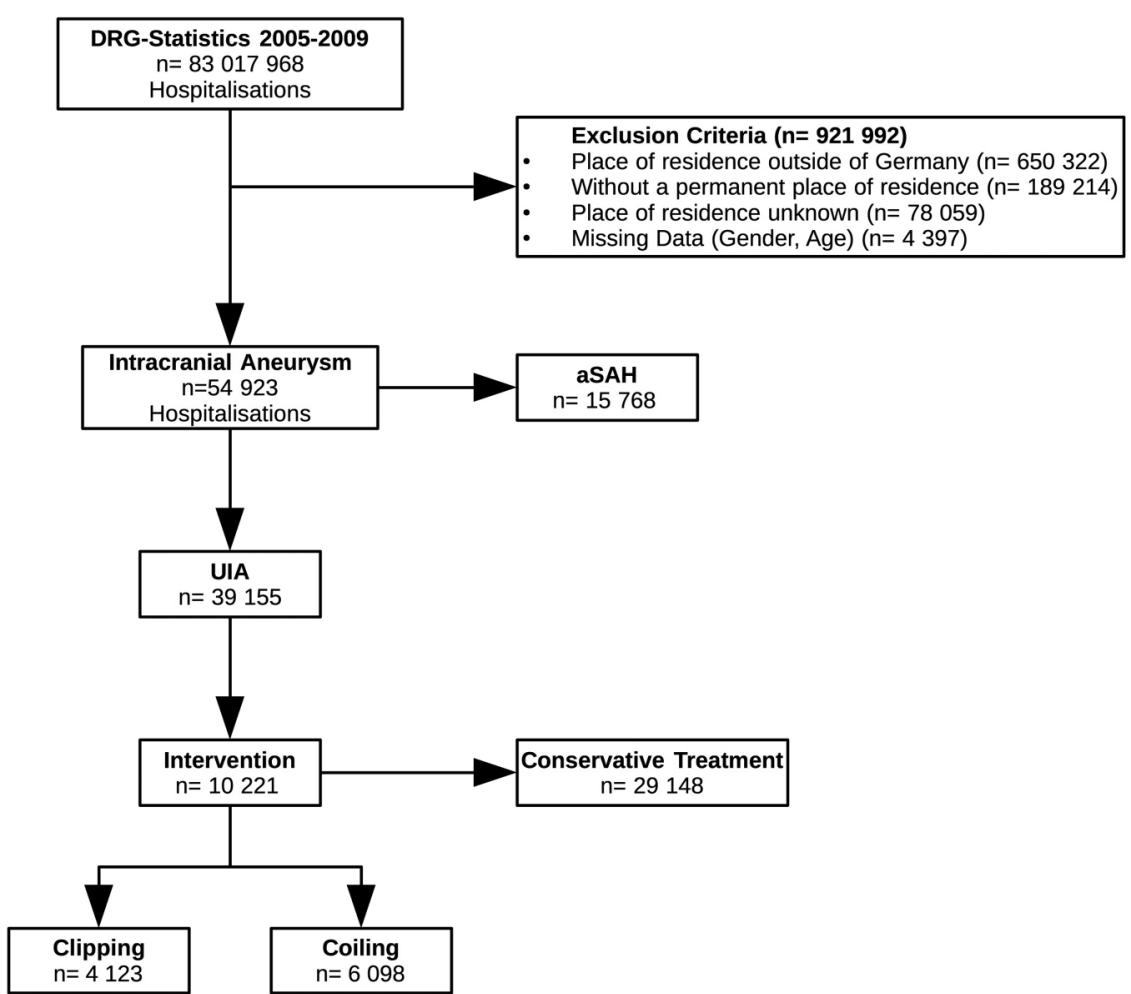


We modified the Charlson comorbidity index (CCI) ${ }^{14}$ to assess comorbidities. We removed acute events (eg, acute myocardial infarction, acute stroke, acute renal failure and acute liver failure) from the CCI, so the modified CCI (mCCI) contains only comorbidities of chronic nature (see online supplementary table S1). We also eliminated ICD-10 codes for UIA from the mCCI (ICD-10-GM: I67.10).

\section{Primary and secondary end points}

The unit of analysis was the hospital admission with an UIA where coiling or clipping was used as treatment. We calculated crude-specific and age-specific rates by gender and region (Federal State, and East and West Germany), respectively. We calculated the overall annual hospitalisation rates, which included any hospitalisation for UIA.

We further assessed mortality, LOS and ventricular shunt implantation associated with the different treatment forms.

\section{Statistical methods}

Annual age-specific (5-year age groups) and age-standardised rates (ASR) were calculated for each treatment modality (ie, coiling and clipping). We used the midyear population of Germany in 2007, provided by the Federal Bureau of Statistics, for direct age standardisation (see online supplementary table S2). We calculated annual rates separately for each year. We used inverse variance weighting for estimating pooled rates and corresponding SEs for the period 2005-2009.

To quantify region-specific and gender-specific differences of the rates of UIA treatment, we calculated standardised rate ratios (SRRs) for the different treatment modalities and their respective $95 \%$ CIs. ${ }^{15}$ We geographically mapped hospitalisations using the patient's place of residence as the reference.

We used a linear regression model to assess the influence of the treatment modalities, age, gender and comorbidities on the mean duration of hospital stay measured in days. Minimal sufficient adjustment sets for potential confounders were determined by use of directed acyclic graphs (DAG). ${ }^{16}$ We used multivariable proportional hazards regression models to estimate adjusted HRs for in-hospital mortality. The proportional hazards assumption was checked by Schoenfeld residual plots. ${ }^{17}$ The time period at risk was the length of hospital stay. The clipped population was used as reference group. All calculations were carried out using SAS V.9.2 (SAS Institute, Cary, North Carolina, USA). We used a DAG software program for the analysis of DAG (program V.0.21).

\section{RESULTS}

Hospitalisations in numbers

From 2005 to 2009, overall 10221 hospitalisations were with UIA diagnosis and coiling or clipping as the associated therapy occurred. Among these hospitalisations, we identified $6098(59.7 \%)$ and 4123 (40.3\%) hospitalisations that included coiling and clipping, respectively. Coiling and clipping during the same hospital stay was coded in $107(0.3 \%)$ hospitalisations for UIA. Sixty-eight per cent of all hospitalisations for UIA occurred among women (table 1). The average age at hospitalisation with UIA was 52.5 (SD 12.6) years for men and 53.5 (SD 11.7) years for women.

\section{Temporal development of ASR}

In 2005, the age-standardised hospitalisation rate per 100000 person years for coiling was 0.7 (95\% CI 0.62 to 0.78 ) for men and 1.7 (95\% CI 1.58 to 1.82 ) for women. In 2009, the ASR was 1.0 (95\% CI 0.90 to 1.10 ) and 2.4 (95\% CI 2.24 to 2.56 ), respectively (figure 2 ). The estimated annual percentage increase for coiling was $9.9 \%$ (95\% CI $7.7 \%$ to $12.2 \%$ ) and $9.8 \%$ (95\% CI $5.7 \%$ to $14.1 \%$ ), for men and women, respectively. Similarly, the ASR for clipping in 2005 amounted to 0.6 (95\% CI 0.52 to 0.68 ) for men and 1.1 (95\% CI 1.00 to 1.20 ) for women. These rates increased in 2009 to 0.8 (95\% CI 0.72 to 0.88 ) and 1.7 (95\% CI 1.58 to 1.82 ), respectively (figure 2).

The estimated annual per cent change of ASR for clipping was $8.3 \%$ (95\% CI $3.5 \%$ to $13.5 \%$ ) and $11.8 \%$ (95\% CI $8.5 \%$ to $15.2 \%$ ), for men and women, respectively. We further observed an increase of ASR for both genders and all treatment modalities (figure 2). Overall hospitalisation rates for UIA with coiling and clipping combined increased by $39.5 \%$ (95\% CI $24.7 \%$ to $56.0 \%$ )

Table 1 General characteristics of hospitalisations of unruptured intracranial aneurysm treated in Germany 2005 to 2009

\begin{tabular}{|c|c|c|}
\hline & Coiling & Clipping \\
\hline Total number $(n=10221)$ & 6098 & 4123 \\
\hline \multicolumn{3}{|l|}{ Gender, \% (n) } \\
\hline Men & $\begin{array}{l}28.6(n=1 \\
744)\end{array}$ & $\begin{array}{l}32.0(n=1 \\
319)\end{array}$ \\
\hline Women & $\begin{array}{l}71.4(n=4 \\
354)\end{array}$ & $\begin{array}{l}68.0(n=2 \\
804)\end{array}$ \\
\hline \multicolumn{3}{|l|}{ Mean age in years (SD) } \\
\hline Men & $53.4(12.7)$ & $51.5(12.4)$ \\
\hline Women & $54.1(12.1)$ & 52.9 (11.3) \\
\hline $\begin{array}{l}\text { Charlson comorbidity index } \\
(\mathrm{SD})^{*}\end{array}$ & $1.17(1.0)$ & $1.45(1.0)$ \\
\hline $\begin{array}{l}\text { Mean length of stay in days } \\
\text { (SD) }\end{array}$ & $8(9.2)$ & $16(10.1)$ \\
\hline \multicolumn{3}{|l|}{ In-hospital mortality, \% (n) } \\
\hline Men & $1.38(n=24)$ & $2.65(n=35)$ \\
\hline Women & $0.94(n=41)$ & $2.00(n=56)$ \\
\hline $\begin{array}{l}\text { Ventricular shunt placement, } \\
\% \text { (n) }\end{array}$ & $0.6(n=34)$ & $1.7(n=70)$ \\
\hline $\begin{array}{l}\text { Temporary ventricular } \\
\text { drainage, \% (n) }\end{array}$ & $1.5(n=94)$ & $6.3(n=259)$ \\
\hline
\end{tabular}



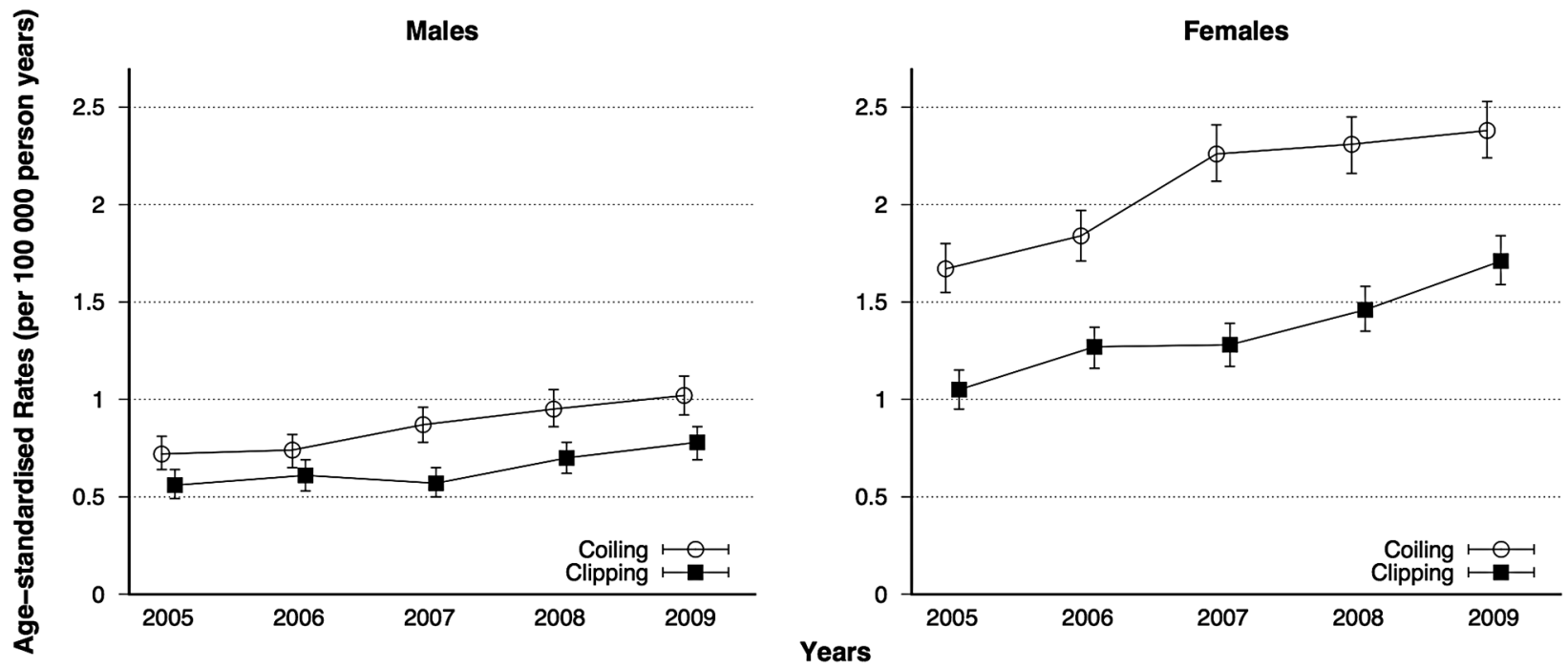

Figure 2 Time trends of age-standardised hospitalisation rates by treatment modalities from 2005 to 2009 in Germany (per 100000 person years, $95 \% \mathrm{Cl}$ ).

Table 2 ASR of treatment modalities (per 100000 person years) of unruptured intracranial aneurysm in Germany 20052009

\begin{tabular}{|c|c|c|c|c|c|c|}
\hline \multirow[b]{2}{*}{ Gender } & \multicolumn{2}{|l|}{ Coiling } & \multicolumn{2}{|l|}{ Clipping } & \multicolumn{2}{|l|}{ Total } \\
\hline & Men & Women & Men & Women & Men & Women \\
\hline ASR (SE) & $0.8(0.15)$ & $2.1(0.02)$ & $0.6(0.07)$ & $1.3(0.02)$ & $1.4(0.03)$ & $3.4(0.04)$ \\
\hline Combined ASR (SE) & \multicolumn{2}{|c|}{$1.5(0.02)$} & \multicolumn{2}{|c|}{$1.0(0.02)$} & \multicolumn{2}{|c|}{$1.5(0.04)$} \\
\hline SRR gender $(95 \% \mathrm{Cl})^{\star}$ & \multicolumn{2}{|c|}{$2.4(1.96$ to 3.05$)$} & \multicolumn{2}{|c|}{$2.1(1.76$ to 2.41$)$} & \multicolumn{2}{|c|}{2.5 (1.63 to 1.88$)$} \\
\hline Increase of ASR (ASR-2009/ & $0.4(0.21$ to & 0.4 (0.29 to & $0.4(0.16$ to & $0.6(0.45$ to & $0.4(0.25$ to & 0.5 (0.39 to \\
\hline ASR-2005) & $0.63)$ & $0.57)$ & $0.63)$ & $0.83)$ & $0.56)$ & $0.62)$ \\
\hline ASR-East (SE)† & $0.7(0.04)$ & $1.4(0.06)$ & $0.5(0.03)$ & $1.0(0.05)$ & $1.2(0.05)$ & $2.4(0.07)$ \\
\hline ASR-West (SE) $\ddagger$ & $0.9(0.02)$ & $2.2(0.04)$ & $0.7(0.02)$ & $1.4(0.03)$ & $1.6(0.03)$ & $3.6(0.05)$ \\
\hline SRR region $(95 \% \mathrm{Cl}) \S$ & $\begin{array}{l}0.7(0.66 \text { to } \\
0.83)\end{array}$ & $\begin{array}{l}0.6(0.57 \text { to } \\
0.66)\end{array}$ & $\begin{array}{l}0.7 \text { (0.59 to } \\
0.77)\end{array}$ & $\begin{array}{l}0.7(0.61 \text { to } \\
0.74)\end{array}$ & $\begin{array}{l}0.7 \text { (0.65 to } \\
0.78)\end{array}$ & $\begin{array}{l}0.6(0.60 \text { to } \\
0.64)\end{array}$ \\
\hline
\end{tabular}

*SRR with its respective $95 \% \mathrm{Cl}: \mathrm{SRR}_{\text {gender }}=\frac{\mathrm{ASR}_{\text {female }}}{\mathrm{ASR}_{\text {male }}}$.

†Including Brandenburg, Berlin, Mecklenburg West-Pomerania, Saxony, Saxony-Anhalt, Thuringia.

łIncluding Baden-Wurttemberg, Bavaria, Bremen, Hesse, Hamburg, Lower-Saxony, North Rhine-Westphalia, Rhineland-Palatinate,

$\begin{aligned} & \text { Schleswig-Holstein, Saarland. } \\ & \text { §SRR with its respective } 95 \% \mathrm{Cl} \text { : SRR } \\ & \text { region }\end{aligned}=\frac{\text { SSR }_{\text {East }}}{\mathrm{ASR}_{\text {West }}}$.

ASR, age-standardised rates; SRR, standardised rate ratio.

and $50.4 \%$ (95\% CI $39.6 \%$ to $62.1 \%$ ) from 2005 to 2009 among men and women, respectively (table 2). The ASR for coiling increased by $40.9 \% \quad(95 \%$ CI $21.3 \%$ to $63.8 \%$ ) for men and $42.6 \%$ (95\% CI $29.4 \%$ to $57.0 \%$ ) for women from 2005 to 2009. Similarly, the ASR for clipping increased by $37.6 \%$ (95\% CI $16.2 \%$ to $63.0 \%$ ) and $63.0 \%$ (95\% CI $44.8 \%$ to $83.4 \%$ ), respectively.

\section{Geographical variation and gender-specific differences}

The observed ASR (per 100000 person years) varied considerably among federal states. Total hospitalisation rates for UIA treatment were lower in East than West Germany for men (SRR 0.7, 95\% CI 0.65 to 0.78 ) and women (SRR $0.6,95 \%$ CI 0.60 to 0.64 ; table 2). There were remarkable differences between the SRR region for both treatment forms (table 2). The geographical range of overall ASR for coiling was 0.68 (95\% CI 0.48 to 0.88 ) in Saxony-Anhalt and 5.64 (95\% CI 4.76 to 6.52) in Saarland (figure 3). For clipping, the overall ASR ranged between 0.52 (95\% CI 0.34 to 0.70$)$ in Saxony-Anhalt and 2.48 (95\% CI 2.17 to 2.79$)$ in Rhineland-Palatinate (figure 4).

The overall ASR were lower for men compared with women (SRR gender 2.5, 95\% CI 1.63 to 1.88 ; table 2). This finding was most present in the ASR for coiling, where the gender-specific SRR amounted to 2.4 (95\% CI 1.96 to 3.05). We observed the highest ASR for coiling in Saarland for female hospitalisations (3.95, 95\% CI 3.21 to 4.69 ) and the lowest in Saxony-Anhalt $(0.4,95 \%$ CI 0.25 to 0.55$)$, respectively (see online 


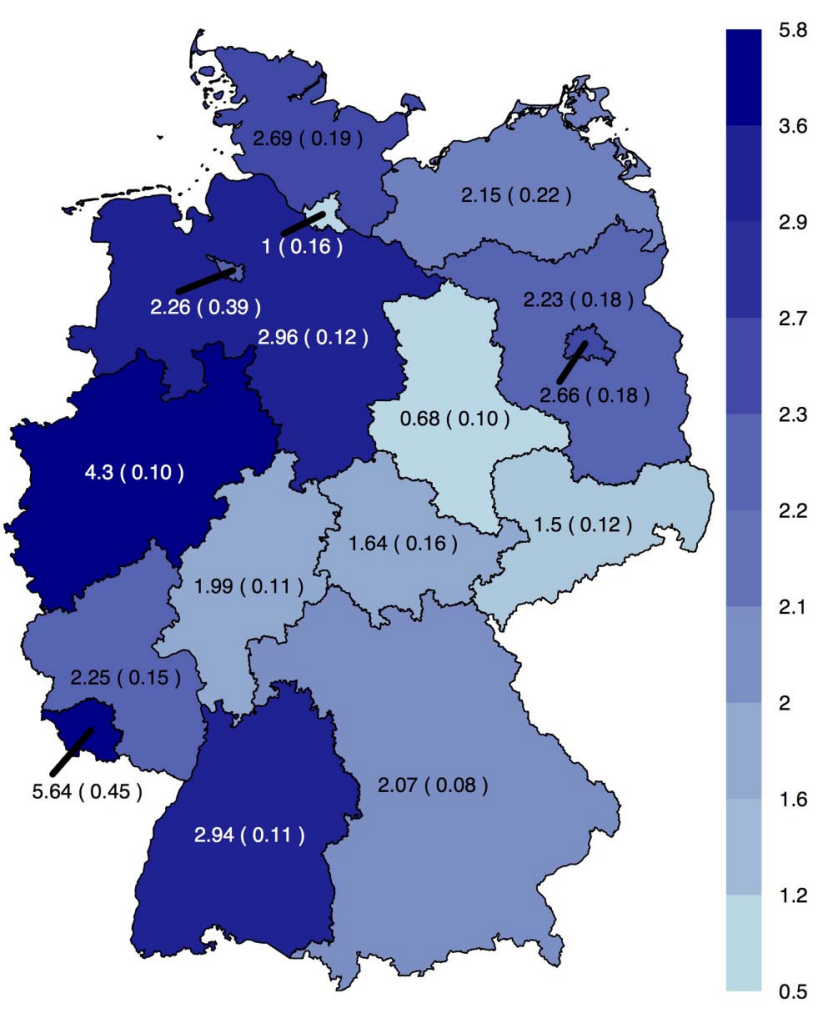

Figure 3 Age-standardised hospitalisation rates for UIA and coiling (men and women) from 2005 to 2009 in Germany (per 100000 person years (SE)). UIA, unruptured intracranial aneurysm.

supplementary figure S1). The geographic distribution pattern was similar for male hospitalisations which received coiling (see online supplementary figure S2). The ASR were 1.69 (95\% CI 1.20 to 2.18 ) and 0.28 (95\% CI 0.15 to 0.41 ), respectively.

In contrast, ASR for clipping in Saarland were comparably low for both men and women (see online supplementary figures S3 and S4).

Age-specific rates, in-hospital mortality, ventricular shunt implantation and LOS

Age-specific rates (per 100000 person years) for coiling and clipping peaked in the age group of 55-59 years (figure 5) for men. The age-specific rates for women receiving coiling or clipping peaked at ages $50-54$ years (figure 5).

Coiling was associated with a lower in-hospital mortality compared with clipping (table 1). The lowest in-hospital mortality occurred among women treated with coiling.

After adjusting for age, gender and mCCI, the estimated HR for in-hospital mortality for coiling-associated hospitalisations was 0.92 (95\% CI 0.66 to 1.28$)$ compared with clipping-associated hospitalisations.

Permanent ventricular shunts were used in $1.7 \%$ $(n=70)$ and $0.6 \% \quad(n=34)$ of hospitalisations associated with clipping and coiling, respectively (table 1 ). Temporary CSF drainages were used in 6.3\% ( $\mathrm{n}=259)$

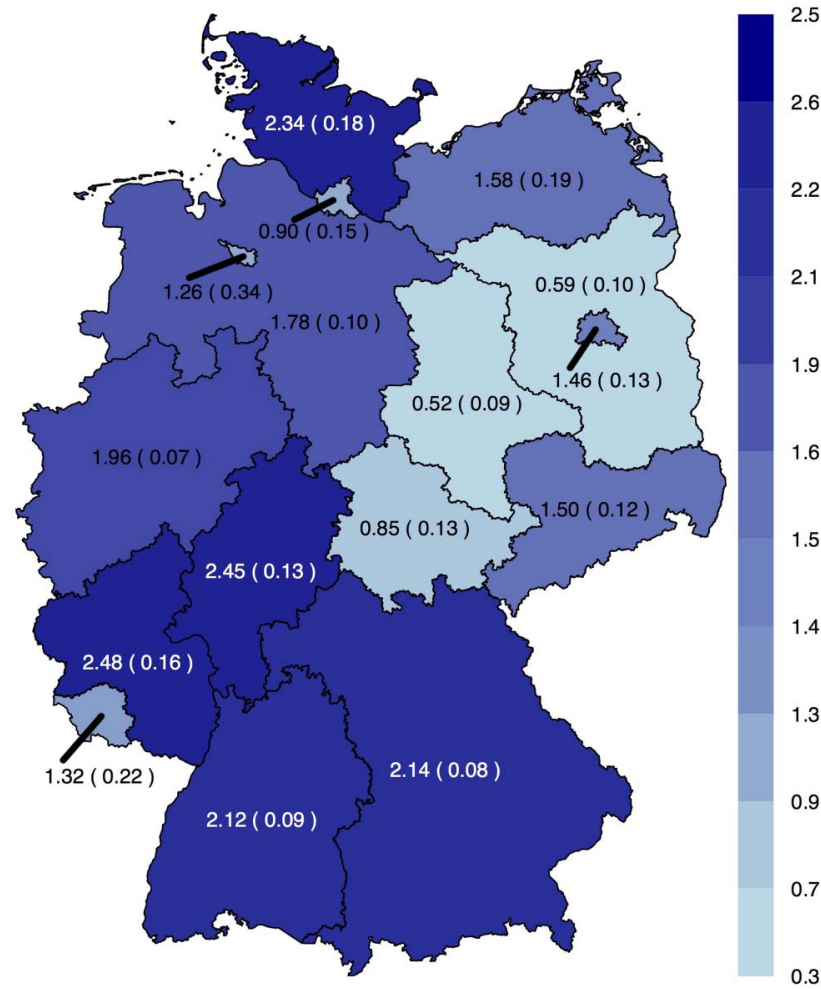

Figure 4 Age-standardised hospitalisation rates for UIA and clipping (men and women) from 2005 to 2009 in Germany (per 100000 person years (SE)). UIA, unruptured intracranial aneurysm.

and $1.5 \%(\mathrm{n}=94)$ of hospitalisations associated with clipping and coiling, respectively (table 1 ).

We found disparities in the LOS among the different treatment modalities. The median LOS was 6 (IQR 5) days in the coiling group and 13 (IQR 9) days in the clipping group (table 1).

After adjusting for age, sex and mCCI, the estimated LOS in linear regression analysis was on average 7.0 (95\% CI 6.6 to 7.4 ) days shorter for coiling, compared with clipping.

\section{DISCUSSION}

\section{Principal findings}

For the first time the nationwide DRG statistics of 20052009 was used to estimate ASR of UIA treatment in Germany. We found a substantial increase in the usage of coiling for UIA treatment during the observation period. Furthermore, we observed an increase in the ASR of clipping. The ASR of coiling for UIA treatment increased by $40.9 \%$ (95\% CI $21.3 \%$ to $63.8 \%$ ) for men and $42.6 \%$ (95\% CI $29.4 \%$ to $57.0 \%$ ) for women. We observed a substantial increase in ASR of clipping in particular for women (table 2 and figure 4).

There were considerable regional differences in the ASR for UIA treatment. We detected the highest ASR of coiling or clipping for Western Germany (table 2). Most strikingly were the differences of ASR for coiling 

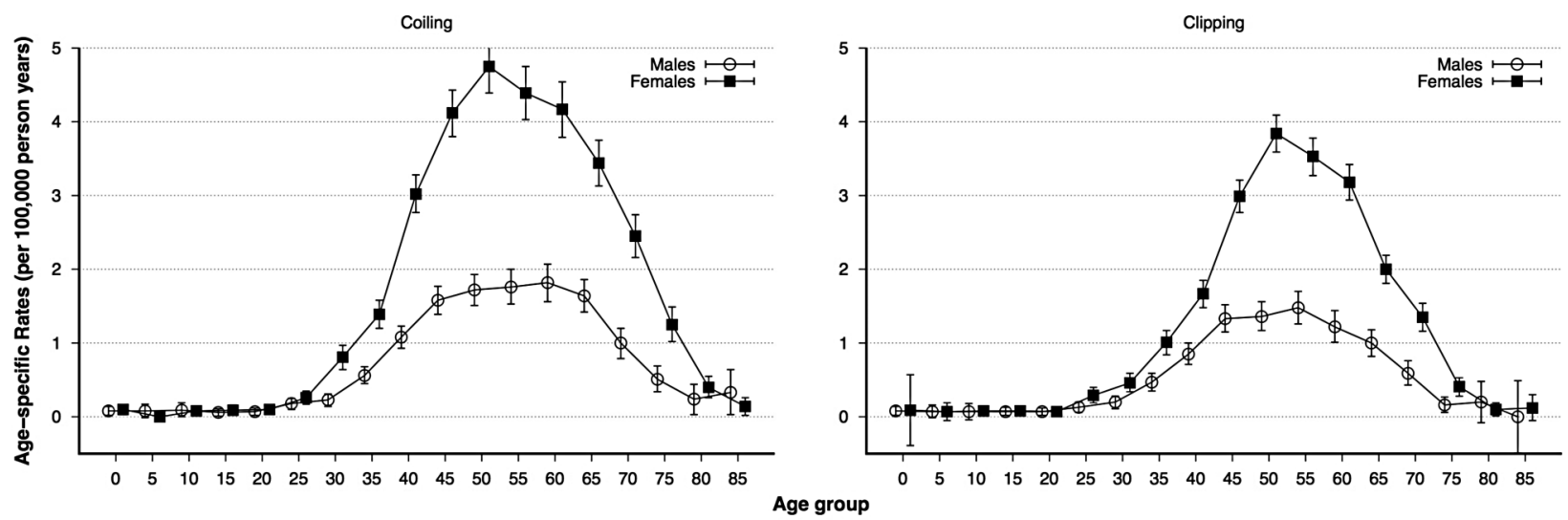

Figure 5 Age-specific rates for UIA treatment from 2005 to 2009 in Germany (per 100000 person years, 95\% Cl). UIA, unruptured intracranial aneurysm.

between Saxony-Anhalt and Saarland (figure 2, online supplementary figures S1 and S2). We also found disparities of ASR between men and women. Women were more present in all treatment groups but in particular in the coiling group. This finding is reflected by the SRR of 2.4 (95\% CI 2.0 to 3.1 ; table 2$)$.

We observed a substantial decline of age-specific rates after the age of 50. This finding was most pronounced in the coiling group (figure 5).

Despite our large data set, the low number of in-hospital deaths related to treatments for UIA resulted in imprecise effect estimation for the difference between clipping and coiling which keeps us from drawing strong conclusions.

The relative frequency of CSF shunt implantation varied depending on treatment allocation of hospitalisations. In hospitalisations where clipping has been used as primary therapy of UIA, we observed a higher number of temporary or permanent CSF shunt implantation compared with the coiling group (table 1).

Furthermore, we observed that hospitalisations treated with clipping had a longer mean LOS. The mean LOS after adjustment for age, sex and mCCI was 7.0 (95\% CI 6.6 to 7.4) days shorter for coiling, compared with clipping.

\section{Comparison with other studies}

We observed a gradual increase of all ASR for hospitalisations with UIA during the observation period. Similar to our findings, Smith $e t a l^{18}$ observed a $40 \%$ increase of relative rates of coiling in UIA treatment for the time period from 2002 to 2008 in the USA. Different to our results Bekelis et $a l^{19}$ report in their analysis of Statewide Planning and Research Cooperative System data from New York State (2009-2013) relative rates of $68.7 \%$ for clipping and $31.3 \%$ for coiling.

Our results show that the majority of hospitalisations are women. An increased risk of aneurysm formation and growth has been described for women in the literature.$^{20}$ Vlak $e t a l^{21}$ reported a higher prevalence of intracranial aneurysm in women aged over 50 years, which they attributed to a possible oestrogen effect. Another group reports a figure of $76.7 \%$ women receiving UIA treatment in New York State. ${ }^{19}$

A potential reason for the observed geographic variation of ASR might be disparities in the adoption of endovascular techniques as observed for the USA. ${ }^{18}$ Smith $e t a l^{18}$ found that geographical variation in the adoption of endovascular techniques to be associated with hospital location. They showed higher usage of endovascular coiling in urban hospitals compared with hospitals in a rural setting. These associations were found to be even stronger when academic hospitals were compared with rural hospitals. Another explanation could be regional variation in UIA prevalence. However, Vlak $e t a l^{21}$ found no regional differences of UIA prevalence in their meta-analysis of studies containing 83 study populations. Similar regional heterogeneity in the treatment of intracranial aneurysm was found by Tykocki et $a t^{22}$ in a recent analysis of discharge data in Poland. The authors concluded that the regional distribution of endovascular treatment centres could be the underlying reason for the observed geographical heterogeneity.

Similar patterns of age-specific rates have been described in the international literature for $\mathrm{UIA}^{7}$ but also for ruptured intracranial aneurysm. ${ }^{7}{ }^{12}{ }^{23-25}$ This is not surprising as the highest UIA prevalence is estimated to be in a population with a mean age of 50 years. ${ }^{21}$ We hypothesise that one possible reason for the unimodal peak of age-specific rates might be that increased age is positively associated with conservative treatment of UIA.

Another publication of NIS data including the time period of 1998- 2007 showed increased in-hospital mortality for UIA cases treated with clipping. ${ }^{2}$ Furthermore, in a study of a $58 \%$ sample of US hospital discharge data, a 2.3-fold (95\% CI 0.97 to 5.7) increase in the odds of in-hospital death was observed, when clipping was used as therapy, compared with coiling. ${ }^{26}$ Owing to our imprecise effect estimation for in-hospital mortality, a direct comparison of our results may not be feasible.

Hoh $e t a l^{27}$ analysed the discharge database of US hospitals for the years 2002 to 2007. In contrast to our results they found no difference in the frequency of CSF 
shunt implantation between coiling and clipping. Alshekhlee $e t a l^{8}$ analysed procedure-associated complications for UIA treatment in NIS data for the years 2000- 2006. They observed higher relative rates of hydrocephalus for coiling compared with clipping. If ventricular shunt implantation and temporary CSF drainage serves as a proxy for hydrocephalus as a treatment-associated complication, this is in contrast to our results (table 1 ).

We observed a shorter mean LOS for hospitalisations treated with coiling. The observed reduction of on average 7.0 days in LOS compared with clipping is in line with international published figures. ${ }^{79}$ Moreover, Higashida $e t a l^{26}$ found an $80 \%$ increase in LOS when clipping was used to treat intracranial aneurysm compared with coiling.

\section{Strengths and weaknesses of the study}

A major strength of this study is the large data set, which includes virtually all German hospitals. This allows a unique view at the current clinical practice. Moreover, to the best of our knowledge, there is currently no other publication addressing this topic from a populationbased viewpoint in Germany.

There are a few limitations to this study. This observational study is based on retrospective hospital data. As we used routine hospitalisation data, we were not able to fully address potential confounding as important clinical factors including aneurysm location, aneurysm size, a history of ischaemic cerebrovascular disease and aneurysm symptoms other than rupture ${ }^{28}$ were not available in the data.

A possible bias affecting the number of UIA-associated hospitalisation might have been readmission. For example, one person harbouring more than one UIA could have contributed more than once to a UIA-associated hospitalisation. Further, reoccurrence of a treated aneurysm could have led to overestimation of ASR in some cases. In a recent publication, a group analysing the New York State wide SPARCS database reported a 30-day readmission rate of $7.36 \%$ for clipping and $6.33 \%$ for coiling, respectively. ${ }^{19}$ These figures have to be interpreted cautiously, as they include readmission for any cause to any hospital in New York State. Furthermore, it is not clear whether the readmission is a postinterventional follow-up or a readmission related to aneurysm reoccurrence.

In addition, we assessed comorbidity based on the coded ICD-10 diagnoses using a mCCI. Comorbidity may be under-reported in the DRG statistics. Furthermore, the derivation of the mCCI was not based on comorbidity assessed at the time of admission. However, as the vast majority of comorbid conditions of the mCCI are chronic conditions, it is unlikely that substantial misclassification came up. Furthermore, the mCCI may not capture specific comorbidities that become relevant for patients with UIA.

\section{CONCLUSIONS}

To the best of our knowledge, we determined for the first time nationwide, representative hospitalisation rates for the treatment of UIA in Germany. The overall ASR of UIA treatment in German hospitals increased substantially. The increase of ASR was higher for clipping compared with coiling throughout the observation period. Even though ASR for clipping were lower compared with the coiling group all ASR showed substantial geographical variation among the different federal states. We observed a numerically lower in-hospital mortality after adjustment for age, gender and comorbidity when coiling was used to treat UIA compared with clipping. Owing to our imprecise effect estimation of HR for in-hospital mortality, no strong conclusion might be drawn from this finding. The implantation rate of temporary and permanent CSF shunts was lower in the coiling group when clipping was used as reference. Finally, we found a shorter LOS when coiling was used to treat UIA.

Contributors VW carried out data collection, analysis, interpretation, drafted the paper and created the figures; AS provided programming structures, carried out data interpretation, reviewed the paper and contracted the data provider.

Funding This research received no specific grant from any funding agency in the public, commercial or not-for-profit sectors.

Competing interests None declared.

Ethics approval The authors were using anonymised data supplied by the German Federal Bureau of Statistics (DESTATIS). The anonymisation of such data is regulated in $\S 16$ Bundesstatistikgesetz (Federal Statistics Act).

Provenance and peer review Not commissioned; externally peer reviewed.

Data sharing statement Raw data are available on request addressed to the corresponding author.

Open Access This is an Open Access article distributed in accordance with the Creative Commons Attribution Non Commercial (CC BY-NC 4.0) license, which permits others to distribute, remix, adapt, build upon this work noncommercially, and license their derivative works on different terms, provided the original work is properly cited and the use is non-commercial. See: http:// creativecommons.org/licenses/by-nc/4.0/

\section{REFERENCES}

1. Rinkel GJE, Djibuti M, Algra A, et al. Prevalence and risk of rupture of intracranial aneurysms : a systematic review. Stroke 1998;29:251-6.

2. Lin N, Cahill KS, Frerichs KU, et al. Treatment of ruptured and unruptured cerebral aneurysms in the USA: a paradigm shift. $J$ Neurointerv Surg 2012;4:182-9.

3. Huang MC, Baaj AA, Downes K, et al. Paradoxical trends in the management of unruptured cerebral aneurysms in the United States: analysis of nationwide database over a 10-year period. Stroke 2011;42:1730-5.

4. Brinjikji W, Lanzino G, Kallmes DF, et al. Cerebral aneurysm treatment is beginning to shift to low volume centers. J Neurointerv Surg 2014;6:349-52.

5. Zacharia BE, Ducruet AF, Hickman ZL, et al. Technological advances in the management of unruptured intracranial aneurysms fail to improve outcome in New York State. Stroke 2011;42:2844-9.

6. Andaluz N, Zuccarello M. Recent trends in the treatment of cerebral aneurysms: analysis of a nationwide inpatient database. J Neurosurg 2008;108:1163-9.

7. Cowan JA, Ziewacz J, Dimick JB, et al. Use of endovascular coil embolization and surgical clip occlusion for cerebral artery aneurysms. J Neurosurg 2007;107:530-5. 
8. Alshekhlee A, Mehta S, Edgell RC, et al. Hospital mortality and complications of electively clipped or coiled unruptured intracranial aneurysm. Stroke 2010;41:1471-6.

9. Hoh BL, Chi YY, Lawson MF, et al. Length of stay and total hospital charges of clipping versus coiling for ruptured and unruptured adult cerebral aneurysms in the Nationwide Inpatient Sample database 2002 to 2006. Stroke 2010;41:337-42.

10. Stang A, Katalinic A, Dieckmann KP, et al. A novel approach to estimate the German-wide incidence of testicular cancer. Cancer Epidemiol 2010;34:13-19.

11. Stang A, Stausberg J. Inpatient management of patients with skin cancer in Germany: an analysis of the nationwide DRG-statistic 2005-2006. Br J Dermatol 2009; 161(Suppl 3):99-106.

12. Walendy V, Strauss $C$, Rachinger $J$, et al. Treatment of aneurysmal subarachnoid haemorrhage in Germany: a nationwide analysis of the years 2005-2009. Neuroepidemiology 2014;42:90-7.

13. Schilling M, Kiefer R, Busse O, et al. Kodierleitfaden Schlaganfall der DSG und DGN 2005. Münster: Schüling Verlag, 2005.

14. Quan $\mathrm{H}$, Sundararajan $\mathrm{V}$, Halfon $\mathrm{P}$, et al. Coding algorithms for defining comorbidities in ICD-9-CM and ICD-10 administrative data. Med Care 2005;43:1130-9.

15. Parkin DM, MacLennan R, Muir CS, et al. Cancer registration: principles and methods (IARC scientific publications). Oxford University Press, USA, 1991.

16. Rothman KJ, Greenland S, Lash TL. Modern epidemiology. 3rd edn Lippincott Williams \& Wilkins, 2008.

17. Schoenfeld D. Partial residuals for the proportional hazards regression model. Biometrika 1982;69:239-41.

18. Smith GA, Dagostino P, Maltenfort MG, et al. Geographic variation and regional trends in adoption of endovascular techniques for cerebral aneurysms. J Neurosurg 2011;114:1768-77.
19. Bekelis K, Missios S, Coy S, et al. New York State: comparison of treatment outcomes for unruptured cerebral aneurysms using an instrumental variable analysis. J Am Heart Assoc 2015;4:e002190.

20. Juvela S, Poussa K, Porras M. Factors affecting formation and growth of intracranial aneurysms: a long-term follow-up study. Stroke 2001;32:485-91.

21. Vlak MH, Algra A, Brandenburg R, et al. Prevalence of unruptured intracranial aneurysms, with emphasis on sex, age, comorbidity, country, and time period: a systematic review and meta-analysis. Lancet Neurol 2011;10:626-36.

22. Tykocki T, Kostyra K, Czyz M, et al. Four-year trends in the treatment of cerebral aneurysms in Poland in 2009-2012. Acta Neurochir (Wien) 2014;156:861-8.

23. Risselada R, de Vries LM, Dippel DWJ, et al. Incidence, treatment, and case-fatality of non-traumatic subarachnoid haemorrhage in the Netherlands. Clin Neurol Neurosurg 2011;113:483-7.

24. Koffijberg H, Buskens E, Granath F, et al. Subarachnoid haemorrhage in Sweden 1987-2002: regional incidence and case fatality rates. J Neurol Neurosurg Psychiatry 2008;79:294-9.

25. Juvela S, Poussa K, Lehto $\mathrm{H}$, et al. Natural history of unruptured intracranial aneurysms: a long-term follow-up study. Stroke 2013;44:2414-21.

26. Higashida RT, Lahue BJ, Torbey MT, et al. Treatment of unruptured intracranial aneurysms: a nationwide assessment of effectiveness. AJNR Am J Neuroradiol 2007;28:146-51.

27. Hoh BL, Kleinhenz DT, Chi YY, et al. Incidence of ventricular shunt placement for hydrocephalus with clipping versus coiling for ruptured and unruptured cerebral aneurysms in the Nationwide Inpatient Sample database: 2002 to 2007. World Neurosurg 2011;76:548-54.

28. Wiebers DO, Whisnant JP, Huston J III, et al, International Study of Unruptured Intracranial Aneurysms Investigators. Unruptured intracranial aneurysms: natural history, clinical outcome, and risks of surgical and endovascular treatment. Lancet 2003;362:103-10. 